\title{
Study of the Stress-strain State of the Process of Drawing Wire from an Alloy of Palladium with Nickel
}

\author{
Sergey SIDELNIKOV ${ }^{1, a}$, Vladimir LOPATIN ${ }^{1}$, Mikhail DOBROVENKO ${ }^{1}$, \\ Ekaterina LOPATINA ${ }^{1}$, Ruslan SOKOLOV ${ }^{1}$ \\ ${ }^{1}$ Siberian Federal University, Russia, 660025, Krasnoyarsk, Krasnoyarskiy Rabochiy ave., 95 \\ ae-mail: sibdrug@mail.ru
}

Keywords: palladium alloy, nickel, wire, drawing, deformation, stress, drawing force.

\begin{abstract}
This article present the results of studies of the process of wire drawing from the PdNi-5 alloy, performed using computer simulation in the DEFORM 3D software package. B качестве материала для исследований использовали сплав с содержанием 95\% палладия и $5 \%$ никеля. An alloy with a content of $95 \%$ palladium and 5\% nickel was a material for research. The patterns of changes in the stress-strain state for the current processing mode determined, and a more rational drawing mode with a redistribution of drawing coefficients along transitions proposed. For the proposed regime, using the created model, the values of drawing stresses, drawing forces and Cockcroft-Latham criterion determined. It was found that the stress distribution in the deformation zone corresponds to the generally accepted laws of their change, and their maximum values are realized in the metal located in the calibrating zone of the drawing die. In addition was revealed that the stresses in the current mode have limit values at the second and fourth passes. The redistribution of deformation indicators in the proposed mode allowed reduce the magnitude of these stresses and, thereby, reduce the likelihood of wire breaks. The maximum value of the Cockcroft-Latham criterion is achieved in the last transitions, but at the same time, destruction will not occur, since they do not exceed the limit value. The drawing force also decreases with the implementation of the proposed mode and does not exceed the permissible values regulated by the technical characteristics of the equipment. Since it is the proposed mode of wire drawing, it is characterized by a decrease in energy power indicators and the likelihood of wire breakage in the process of metal deformation it can be recommend it for implementation in existing production.
\end{abstract}

\section{Introduction}

In the production of nitric acid, platinum serves as a highly effective catalyst [1-3]. The catalysts are made in the form of wire grids with a diameter of from 0.09 to $0.060 \mathrm{~mm}$ with different cell side sizes and cell numbers. Under the influence of high temperatures, the oxidizing medium supplied with the gas, the structure of the catalyst grids changes, in particular, the loosening of their surface layer, an increase in size, which, in turn, leads to loss of mass. Therefore, catalytic systems for the oxidation of ammonia in nitric acid production units are the following combination of grids:

- catalyst grids;

- trapping grids;

- separation grids (they are used to separate catching grids and prevent their sintering during operation).

The trapping grids are made of palladium alloys and placed after the catalyst grids, and the volatilized platinum oxide is transferred by gas flow to their surface, where platinum is reduced and subsequently diffused into the material of the trapping grid. Part of the palladium in the platinum recovery process is lost, but the gain due to trapped platinum covers these losses. As a result of saturation with platinum, trapping grids acquire catalytic properties, which reduces the number of catalyst plaques with a high platinum content in the catalyst package [2].

The aim of this work is to increase the efficiency of wire production technology for the manufacture of trapping grids. 


\section{Methods of carrying out researches}

To achieve this goal, we analyzed the process of wire drawing from the PdNi-5 alloy for the current operating conditions and the proposed modes using computer simulation. The calculation of the drawing routes was carried out according to the method described in $[4,5]$ using the PROVOL program [6], while the plastic properties of the alloy and the technical characteristics of the drum-type drawing machine used to the maximum (Table 1).

Table 1 Technical characteristics of a single drawing mill

\begin{tabular}{|l|c|}
\hline \multicolumn{1}{|c|}{ Parameter name } & The value of the machine parameter \\
\hline Engine power, $\mathrm{kW}$ & 31 \\
\hline Three-phase supply voltage, $\mathrm{V}$ & 380 \\
\hline Current frequency, $\mathrm{Hz}$ & 50 \\
\hline Maximum productivity, $\mathrm{kg} / \mathrm{h}$ & 8 \\
\hline Wire drawing speed, $\mathrm{m} / \mathrm{min}$ & $5-2000$ \\
\hline Permissible drawing force, $\mathrm{kN}$ & 1,5 \\
\hline
\end{tabular}

Eleven dies arranged in a row with a calibrating zone with a diameter from $3.82 \mathrm{~mm}$ to $1.184 \mathrm{~mm}$ and an angle of 6 degrees were used as a drawing tool. The drawing speed was taken equal to $2500 \mathrm{~mm} / \mathrm{s}$, and the conditions for the contact interaction of the workpiece and die according to the Amonton-Coulomb law with a friction index of 0.08 .

SolidWorks volumetric design system used for the design development of tool models (Fig. 1), and the DEFORM 3D software package used to model the drawing process and predict the behavior of the metal under the action of deforming loads and deformation conditions [6].

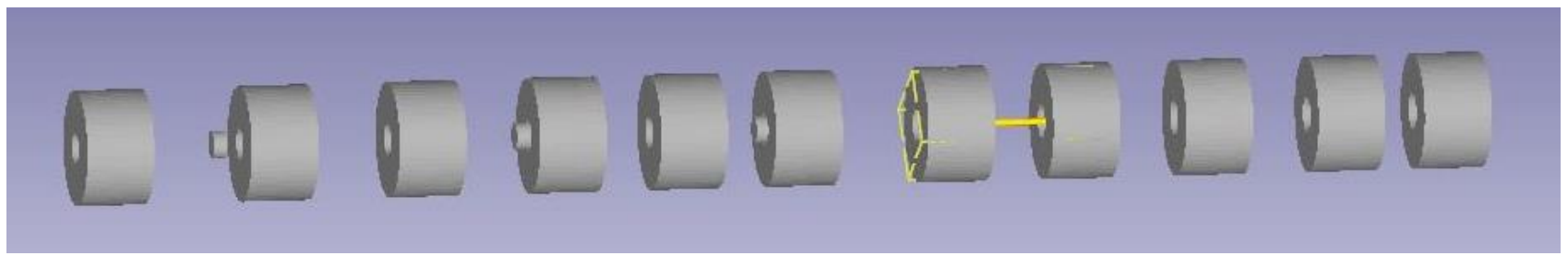

Fig. 1. Assembly model of the drawing process in the DEFORM-3D software package

As the initial conditions for modeling one of the stages of drawing the existing production, the PdNi-5 alloy used the chemical composition of which included $95 \%$ palladium and 5\% nickel. Analysis of the scientific and technical literature [7-19] showed the lack of data on the rheological characteristics of the PdNi-5 alloy in it. To determine them, special experimental studies performed $[8,9]$, as a result of which data obtained on the tensile strength and elongation, the values of which imported into the DEFORM-3D software package.

\section{Results and its discussion}

The Cockcroft-Latham exponent used to assess metal fracture in metal forming [20] and is based on an estimate of the total work of deformation per unit volume at the fracture point was adopted as a fracture criterion:

$$
C_{C-L}=\int_{0}^{\varepsilon_{i}} \frac{\sigma_{1}}{\sigma_{i}} d \varepsilon
$$

where $\varepsilon_{i}$-accumulated strain rate at the time of fracture; $\sigma_{1}-$ main tensile stress; $\sigma_{i}-$ Mises stress intensity.

An analysis of the existing deformation modes of wire drawing (Fig. 2) showed that at the second, third, and eighth passes, the drawing coefficient $\lambda_{\text {sing }}$ is overestimated, which leads to wire breaks at these passes. It is proposed to redistribute and align the drawing ratio by adding 
two additional passes (see Fig. 2). Then the number of passes will be eleven, which will reduce the likelihood of defect during wire drawing.

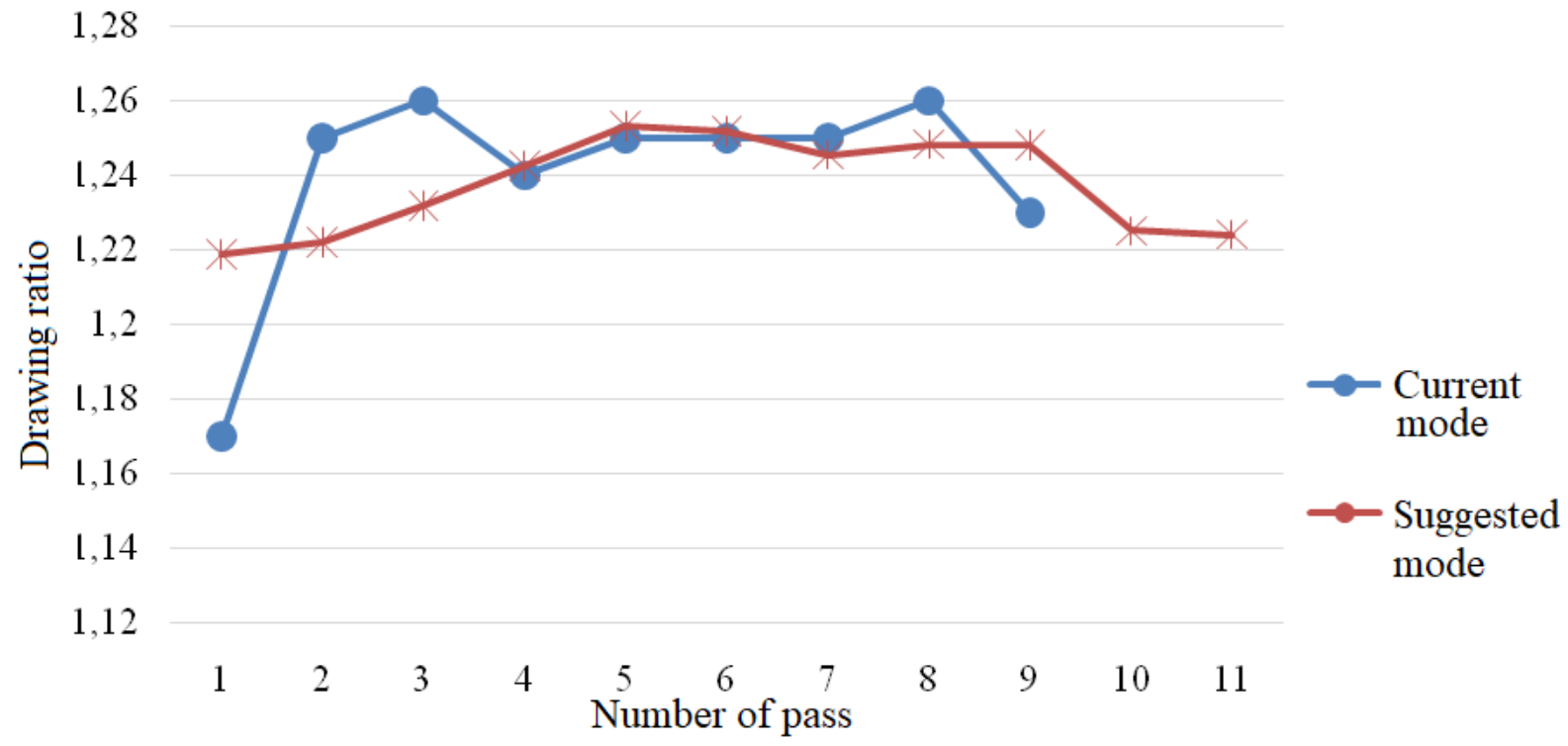

Fig. $2 \mathrm{~A}$ graph of the variation of the drawing ratio $\lambda_{\text {sing }}$ by passes for the current and proposed drawing modes

Simulation of the drawing process made it possible, for given deformation parameters (single $\varepsilon_{\text {sing }}$ and total $\varepsilon_{\sum}$ reduction), to calculate the ultimate tensile strength $R_{m}$ in the deformation zone, as well as to obtain data on the drawing force $P_{\text {draw }}$ and the fracture criterion for $\mathrm{C}_{\mathrm{C}-\mathrm{L}}$ passes (Table 2).

Table 2 Calculation data for the process of drawing the wire from alloy PdNi-5

\begin{tabular}{|c|c|c|c|c|c|c|c|}
\hline $\begin{array}{c}\text { Number of } \\
\text { pass }\end{array}$ & Diameter, mm & $\lambda_{\text {sing }}$ & $\varepsilon_{\text {sing }}, \%$ & $\varepsilon_{\Sigma}, \%$ & $R_{m,} \mathrm{MPa}$ & $P_{\text {draw }}, \mathrm{N}$ & $C_{C-L}$ \\
\hline & 3.82 & & & & & & \\
\hline 1 & 3.46 & 1.22 & 18.0 & 18.0 & 242 & 845.0 & 0.17 \\
\hline 2 & 3.13 & 1.22 & 18.2 & 32.9 & 295 & 726.6 & 0.23 \\
\hline 3 & 2.82 & 1.23 & 18.8 & 45.5 & 336 & 823.2 & 0.32 \\
\hline 4 & 2.53 & 1.24 & 19.5 & 56.1 & 647 & 625.1 & 0.33 \\
\hline 5 & 2.26 & 1.25 & 20.2 & 65.0 & 578 & 505.0 & 0.41 \\
\hline 6 & 2.02 & 1.25 & 20.1 & 72.0 & 538 & 628.7 & 0.23 \\
\hline 7 & 1.81 & 1.25 & 19.7 & 77.6 & 597 & 545.1 & 0.29 \\
\hline 8 & 1.62 & 1.25 & 19.9 & 82.0 & 626 & 530.5 & 0.35 \\
\hline 9 & 1.45 & 1.25 & 19.9 & 85.6 & 649 & 477.0 & 0.42 \\
\hline 10 & 1.31 & 1.23 & 18.4 & 88.2 & 648 & 312.3 & 0.48 \\
\hline 11 & 1.184 & 1.22 & 18.3 & 90.4 & 652 & 247.3 & 0.53 \\
\hline
\end{tabular}

The distribution of drawing stresses in the deformation zone for the proposed modes is shown in Fig. 3. Their analysis makes it possible to assert that the maximum stresses are realized in the metal located in the calibrating zone of the dies, which is fully consistent with traditional ideas about the nature of the stress-strain state during wire drawing. 


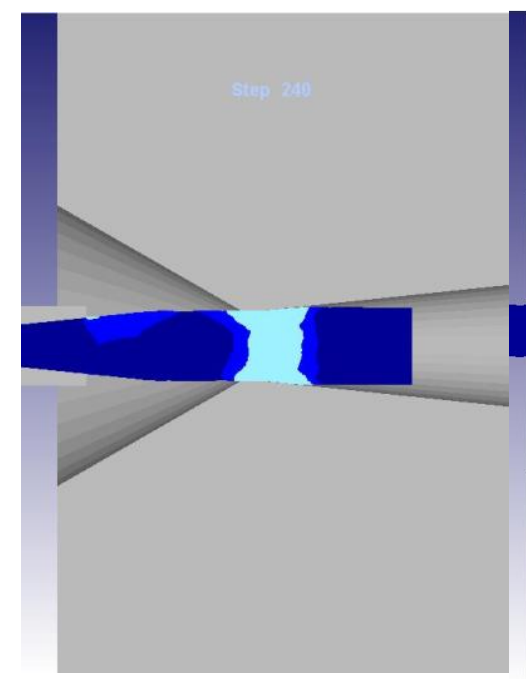

$a$

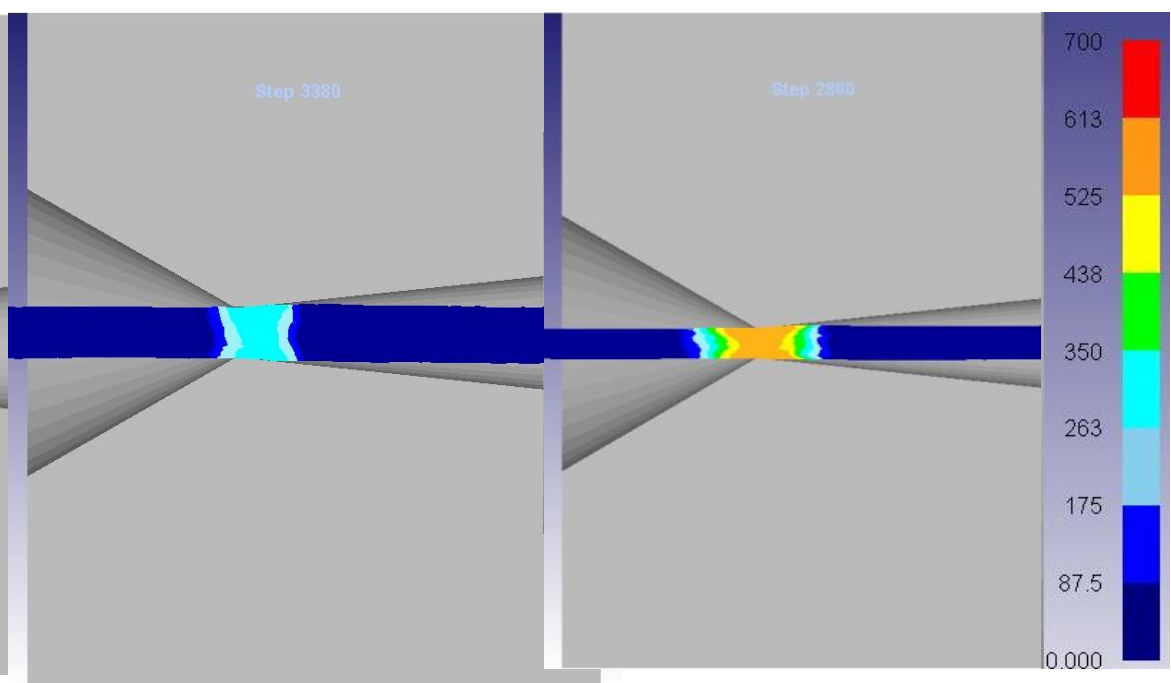

$b$

$c$

Fig. 3. Passes stress distribution for the proposed mode:

$a$ - first pass, $b$ - fifth pass, $c$ - ninth pass

The graph of stresses across passes is shown in Fig. 4. His analysis shows that, compared with the current mode of drawing, there is a decrease in drawing stresses along the passes. A more significant decrease in stress is noticeable in the second and fourth passes. This is due to the redistribution of the drawing ratio coefficient of the current regime and a decrease in a single degree of deformation.

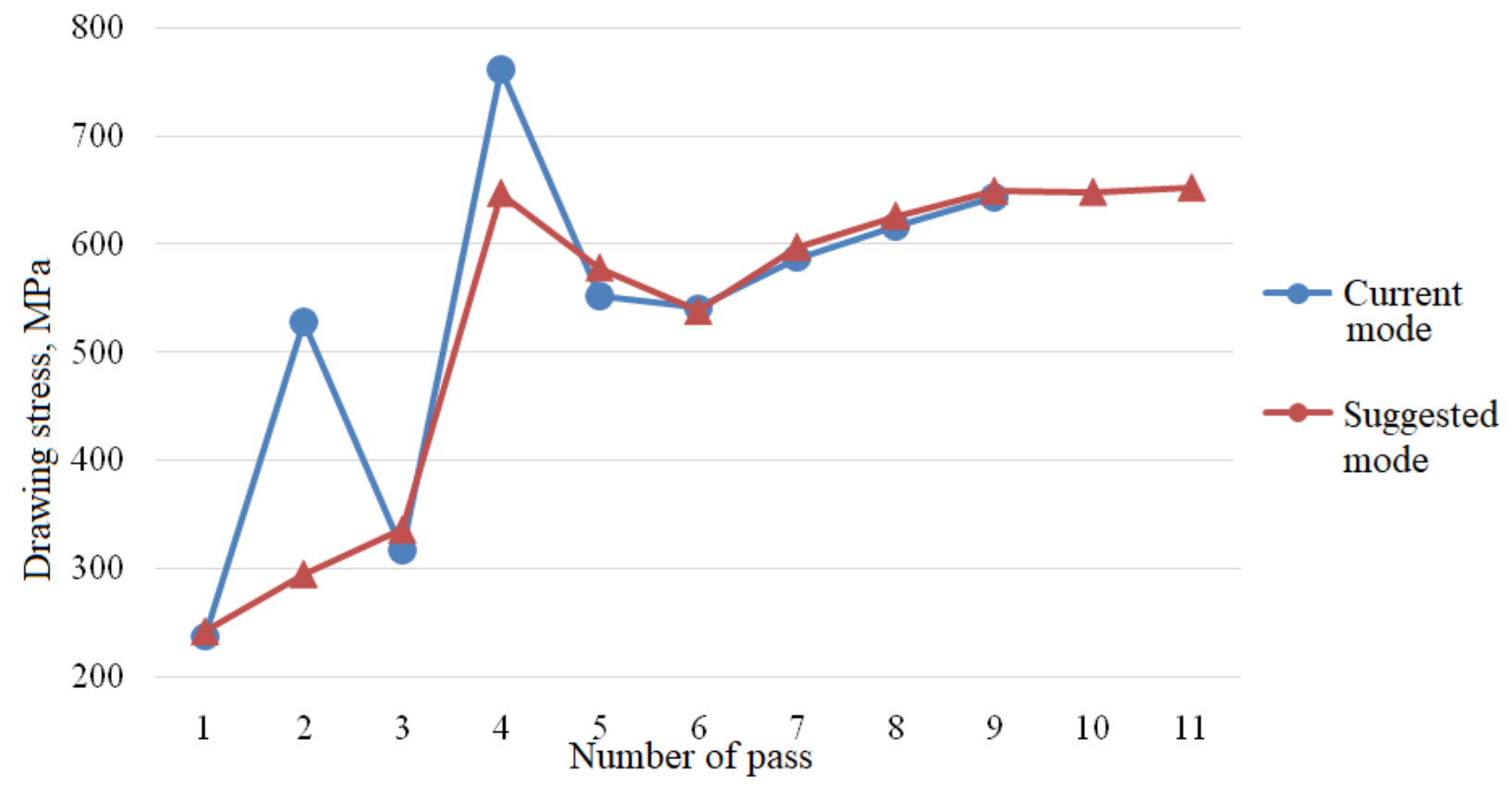

Fig. 4. Passes stress distribution graph for current and proposed modes

The distribution of the Cockcroft-Latham criterion over the deformation zone is shown in Fig. 5, it was found that the maximum value is reached in the last transitions (Table 2), but no destruction will occur, since they do not exceed the limit value. 


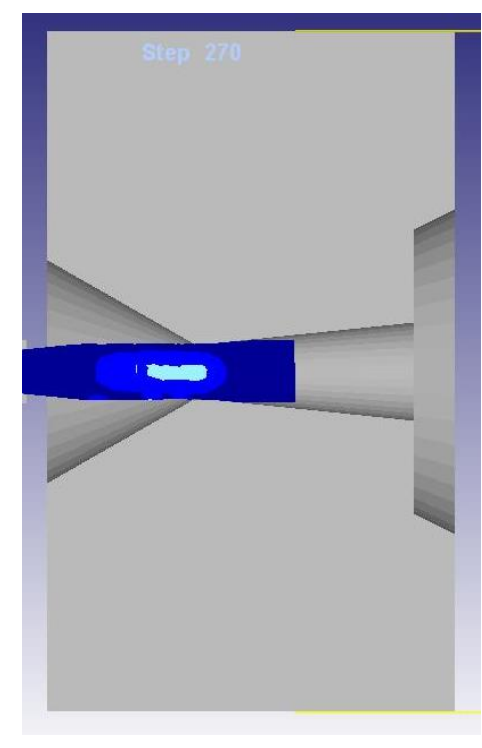

$a$

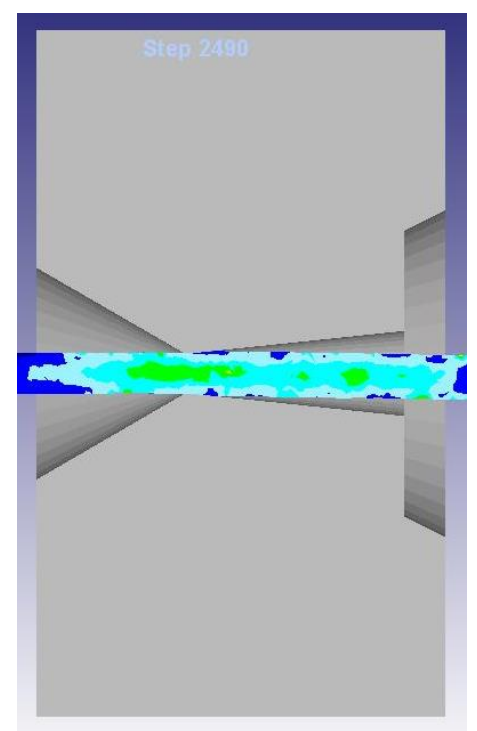

$b$
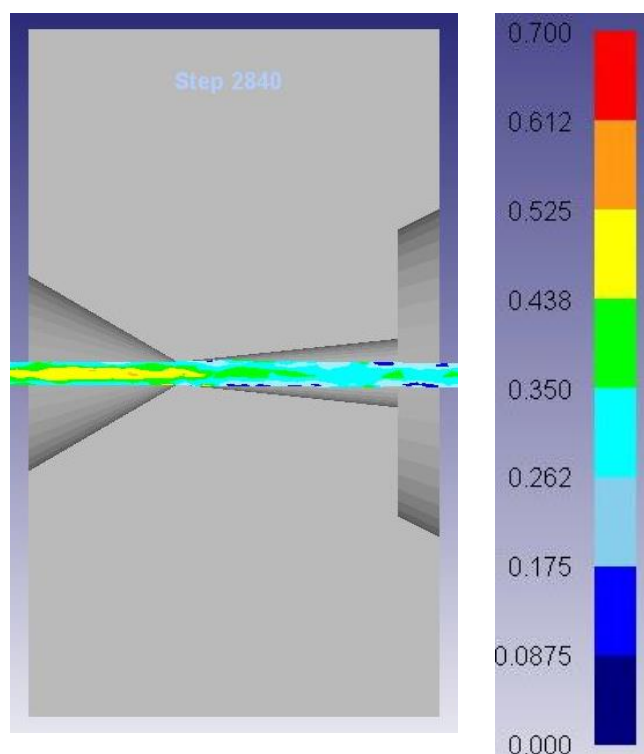

$c$

Fig. 5. Cockcroft-Latham passes distribution for the proposed mode:

$a$ - first pass, $b$ - fifth pass, $c$ - ninth pass

Analysis of changes in the drawing force along passes (Fig. 6) shows that its value decreases with the implementation of the proposed regime and does not exceed the permissible values regulated by the technical characteristics of the equipment (Table 1).

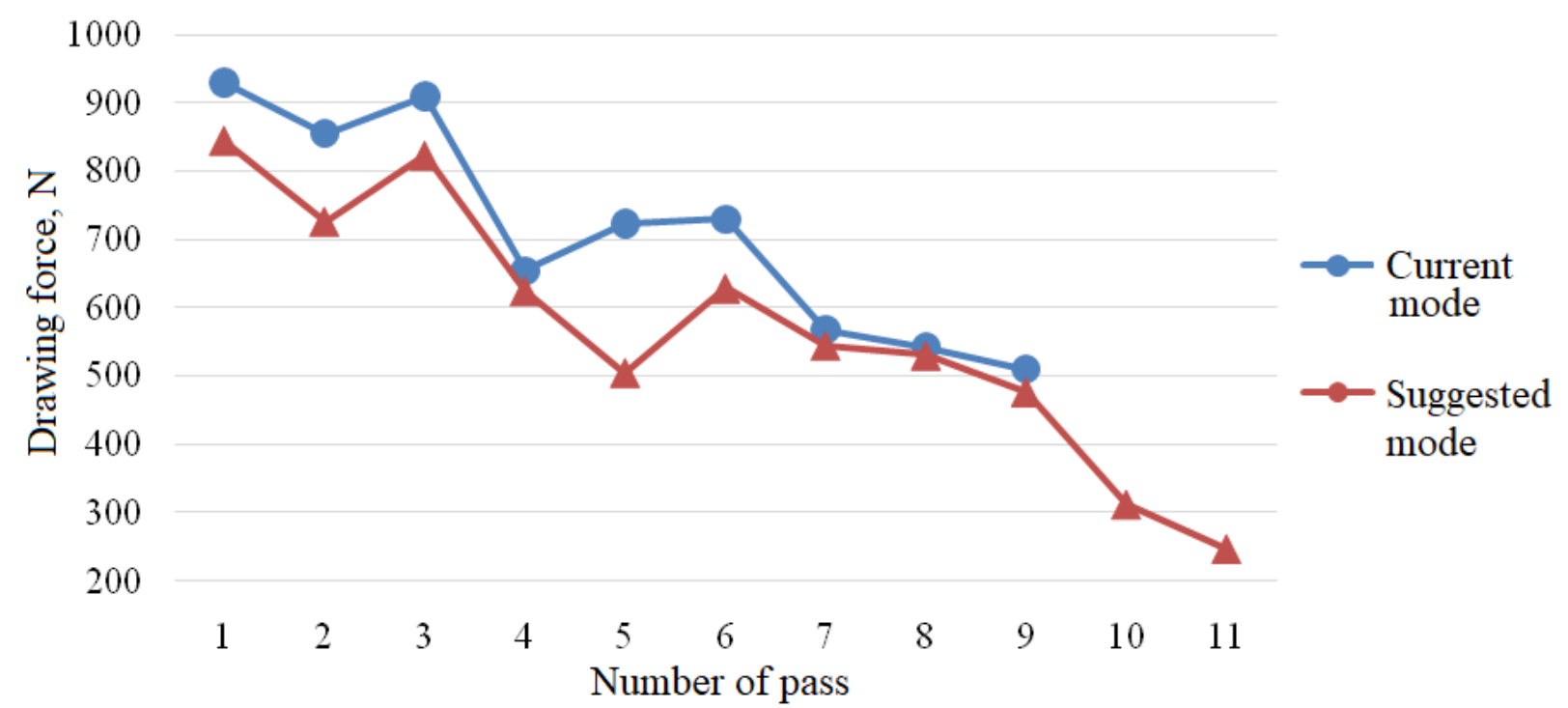

Fig. 6. Graph of changes in drawing force on passes for the current and proposed drawing modes

\section{Conclusion}

Thus, as a result of studies using computer simulation, the distribution of stress-strain state indicators was determined when drawing a wire with a diameter of $1.184 \mathrm{~mm}$ from alloy and the patterns of their change in drawing transitions were determined. The results obtained make it possible to recommend the proposed mode of wire drawing, since it is characterized by a decrease in energy-power indicators, and the likelihood of wire breakage in the process of metal deformation.

\section{References}


[1] Il'in A.P., Kunin A.V., Il'in A.A. Nitric acid production: a tutorial. Ivan. State chem.-tech. Un-ty. Ivanovo, 2011.

[2] Karavaev M.M., Zasorin A.P., Kleshchev N.F. Ammonia catalytic oxidation. M: Chemistry, 1983.

[3] Korobochkin V.V. Nitric Acid Technology: A Tutorial. Tomsk: Publ. Tomsk polytech. Unty, 2012.

[4] Ivanov E.V. Drawing technology: teaching aid. SibFU. Krasnoyarsk, 2012.

[5] Zagirov N.N., Konstantinov I.L., Ivanov E.V. Basics of calculations of processes for producing long metal products by metal forming methods: textbook. SibFU. Krasnoyarsk, 2011.

[6] Certificate of state registration of the computer program PROVOL №2015612273 RF / S.B. Sidelnikov, S.V. Belyaev, O.S. Lebedeva, Yu. D. Ditkovskaya, E.S. Leontieva, E.A. Rudnitsky, A.S. Solyanikova. Patento owner of FGAOU VPO "Siberian Federal University."- № 2014663306; claimed. 12/19/2014; publ. 02/16/2015.

[7] Sidelnikov S.B., Dovzhenko N.N., Gubanov I.Yu. [and others]. Modeling and computeraided design of technological processes of metal processing: a training manual. SibFU. Krasnoyarsk, 2007.

[8] Sidelnikov S.B., Bindareva K.A., Lopatina E.S., Leonov V.V., Voroshilov D.S., Lebedeva O.S., Rudnitsky E.A., Lopatin V.A. Computer Simulation and Analysis of the Parameters of the Drawing Process of Thin Wire from the Alloy Pd-5Ni. Key Engineering Materials. 2019. Vol. 805, pp 13-18.

[9] Bindareva K.A. The study of the mechanical properties of semi-finished products from alloy PdNi-5 with varying degrees of purity. Prospect Svobodny - 2018: International Student Conference Proceedings. Krasnoyarsk: SibFU, (2018) 1059-1061.

[10] Ivanović T.A. Petković B. B. [and other]. Optimisation of the Recrystallisation Annealing Regime of Pd-5Ni Alloy // Journal Johnson Matthey Technol. Rev., 2016. - p. 60.

[11]Pavlov E.A., Gurskaya V.Yu., Gushchinskiy A.A., Efimov V.N. Justification and selection of the cooling mode of the alloy PdNi-5 during the solidification of the ingot. Tsvetnye metally. 11 (2010) 46-50.

[12] Konstantinov I.L. Materials science of precious metals: tutorial. Krasnoyarsk: IPK SFU, 2009.

[13] Brepol E. Theory and practice of jewelry. "Solo". St. Petersburg, 2000. - 528 p.

[14] Novikov I.I, Zolotorevskiy V.S., Portnoy V.K. [and others] Metal science: textbook in 2 t. T1. Fundamentals of Metal Science. Moscow: Publ. MISiS, 2014.

[15] Flanagan T.B., Noh H., Wang D. Hydrogen isotherms for compositionally homogeneous and inhomogenous Pd1-xNix alloys. Journal of Alloys and Compounds. 2018. Vol. 750, pp 599606.

[16] Gang C., Peng Z., Hongwei L. Molecular dynamics simulation of solidification of Pd-Ni clusters with different nickel content. Advances in Materials Science and Engineering. 2014. Vol. 2014, № 926206.

[17]Bagmut A.G., Shipkova I.G., Zhuchkov V.A. Formation, structure, and magnetic changes at annealing of films deposited by laser sputtering of $\mathrm{Ni}$ and Pd. Journal of Surface Investigation. 2011. Vol. 5, Issue 3, pp 460-464.

[18]Kang Z., Zhao M., Wu Y., Xia T., Cao J.-P., Cai W., Chen L. Facial fabrication of yolkshell Pd-Ni-P alloy with mesoporous structure as an advanced catalyst for methanol electrooxidation. Applied Surface Science. 2019. Vol. 484, pp 441-445.

[19]Guo M., Wang H., Cui L., Zhang J., Xiang Y., Lu S. Nickel Promoted Palladium Nanoparticles for Electrocatalysis of Carbohydrazide Oxidation Reaction. Small. 2019. Vol. 15, Issue 28, № 1900929.

[20] Matveev M.A. Numerical estimation of the probability of metal failure under hot plastic deformation by means of the Cockroft-Latham criterion. Scientific-technical Bulletin of SPbSPU. Natural and engineering Sciences. 2017. Vol. 23. No.2. P. 109-126. 